\title{
Experimental studies and numerical simulation of coolant hydrodynamics in the inlet area of nuclear reactor fuel assembly
}

\author{
Sergei Dmitriev ${ }^{1}$, Alexander Khrobostov ${ }^{1}$, Maksim Legchanov $^{1}$, and Alexander Dobrov ${ }^{1, *}$ \\ ${ }^{1}$ Nizhniy Novgorod State Technical University n.a. R.E. Alekseev, Minin St., 24, Nizhniy Novgorod, \\ 603950, Russia
}

\begin{abstract}
An innovative core with an increased energy resource was used when designing RITM-200 reactor unit. The paper presents the results of experimental and numerical simulation of hydrodynamic processes occurring in the inlet region of the RITM reactor fuel assembly model. Computational mesh of fuel assembly, containing $\sim 22$ million elements was created using Ansys ICEM CFD. The values of relative axial velocities in several cross sections at the inlet to the bundle of fuel elements are obtained. At the inlet to the fuel rods bundle the velocity field is not uniform, due to the complex geometry of the fuel assembly. The obtained results of CFDsimulation can be used to determine the input boundary conditions for subchannel programs of the core thermal-hydraulic analysis. This allows taking into account uneven flow rate distribution in subchannels due to the complex geometry of the fuel assembly inlet region.
\end{abstract}

\section{Introduction}

An innovative core with an increased energy resource was used when designing RITM-200 reactor unit. Fuel assemblies are enclosed in hexagonal covers, installed central displacer with a safety control rod and fuel rods bundle [1-11]. The design features of the fuel assembly necessitated the determination of important hydraulic characteristics, such as the distribution of the coolant flow rate in the subchannels at the inlet to the fuel rods bundle.

The most accurate method of obtaining these data can be an aerodynamic experiment using an enlarged model of the fuel assembly [12-15]. However, taking into account the active use of CFD programs for thermal-hydraulic calculations in nuclear industry [16-20], the authors of this work carried out a numerical simulation of the coolant flow in the fragment of a fuel assembly using Ansys CFX. The results of the calculations were compared with the experimental data in order to evaluate the capabilities of the selected program for carrying out similar studies.

\footnotetext{
* Corresponding author: a_v_ryazanov@ rambler.ru
} 


\section{Description of the experimental test bench and research methods}

The experimental test bench FT-50, which is a high-pressure aerodynamic open loop, is designed to investigate the local hydrodynamic characteristics of the coolant flow in fuel assembly models, as well as the verification of CFD programs. The general view of the experimental test bench is shown in figure 1 .

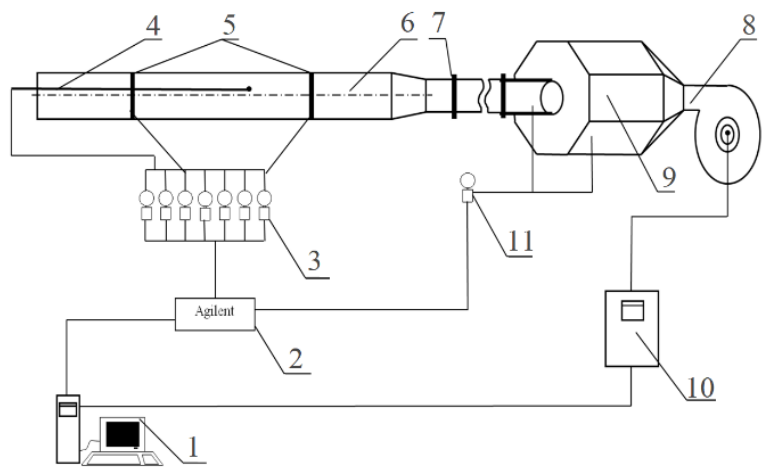

Fig. 1. The general view of the experimental test bench FT-50. 1 - the personal computer; 2 - data acquisition system; 3 - pressure sensors; 4 - Pito-Prandtl pneumometric probe; 5 - pressure measurement section; 6 - experimental model; 7 - a throttle washer; 8 - high-pressure fan; 9 - buffer tank; 10 frequency converter, 11 - differential pressure flowmeter.

The experimental model of a cassette fuel assembly consists of an inlet region and a fragment of the fuel rods bundle up to the first spacing grid. The geometry and dimensions of the model correspond to the real ones with an enlarged scale. The schematic diagram of the experimental model is shown in figure 2.

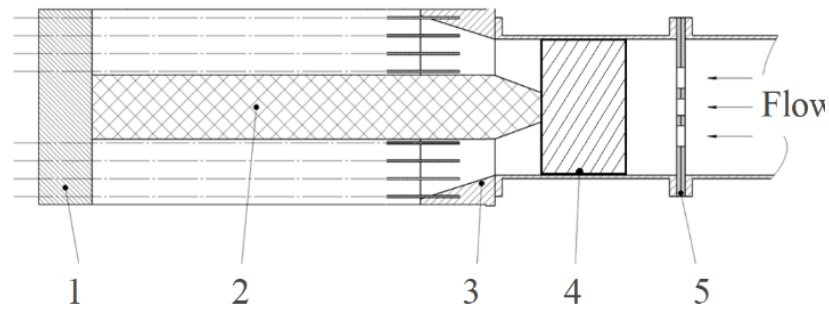

Fig. 2. The schematic diagram of the experimental model. 1 - spacer grid; 2 - displacer; 3 - diffuser; 4 -sleeve; 5 - throttle washer.

To study the distribution of the axial component of the coolant velocity, the cross section in the bundle of fuel rods was conditionally broken up into 168 subchannels. The subchannel was the volume occupied by the coolant between a group of neighboring fuel rods. The pneumometric probe was placed in the center of each subchannel with a rigidly fixed coordinate device. The measurements were made in several cross sections along the length of the model.

\section{Description of numerical model of fuel assembley}

The CFD model of cassette fuel assembly was created on the same scale as the experimental model using Ansys ICEM CFD. In this case, by virtue of the symmetry conditions, only half of the fuel assembly was considered. This allowed us to reduce the number of mesh elements 
and simplify the requirements for computing resources. The automatic grid was generated using ICEM CFD. At the same time, in the inlet region of the fuel assembly a tetrahedral mesh was generated, which was then extruded along the fuel rods bundle. The size of the mesh elements was chosen from the conditions of equality to $1 / 20$ of hydraulic diameter. In the near-wall region, the height of prismatic mesh elements was selected based on the condition $y^{+}=1 \div 5$. Figure 3 shows a general view of the computational mesh, containing of $\sim 22$ million elements.

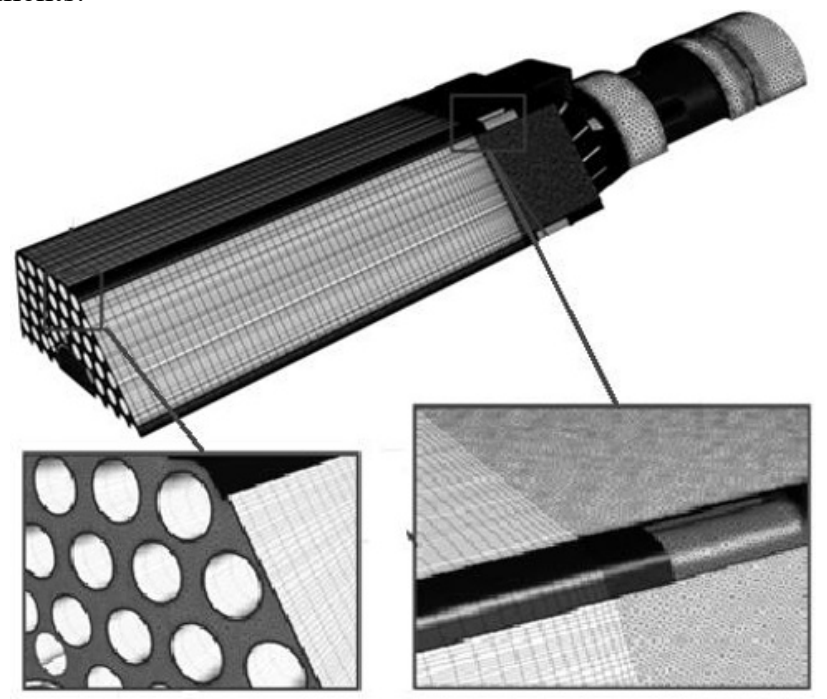

Fig. 3. Computational mesh

The CFD simulation was carried out using Ansys CFX. To close the system of NavierStokes equations the shear stress transport (SST) turbulence model was employed. The boundary conditions were given as follows:

- coolant mean velocity was the same as in the experiment;

- $\quad$ static pressure at the outlet boundary;

- symmetry boundary condition.

\section{Results}

As a result of computational and experimental studies, the distribution of the coolant velocity in different sections of the fuel assembly was obtained. The data were analyzed as relative velocities, which are the ratio of the local coolant velocity to the mean velocity. A quantitative comparison of the calculated values of the relative velocity was carried out for the points located at the centers of the subchannels. Figures 4 and 5 show the values of the relative velocity in the fuel assembly subchannels obtained as a result of numerical simulation and an experimental study for several cross sections.

At the inlet to the fuel rods bundle the velocity field is not uniform due to the complex geometry of the fuel assembly. The maximum calculated values of the relative velocity in subchannels reach 1.8. In the experiment, such values were not observed, and the maximum relative velocity was 1.55 . The main difference between the calculation and experiment is found in the subchannels located near the hexagonal cover of the fuel assembly. The rootmean-square deviation of the relative velocity from the experiment, determined from all subchannels of the outlet cross-section of the fuel assembly, was $15.9 \%$ for the SST turbulence model. 


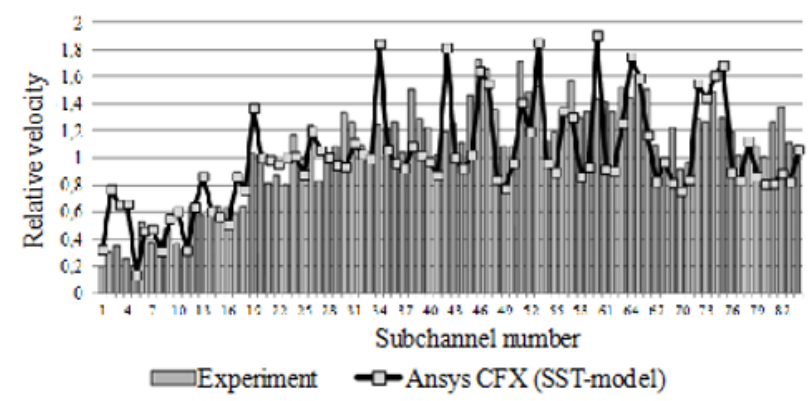

Fig. 4. Relative velocity distribution by subchannels in the inlet cross-section of the bundle of fuel elements

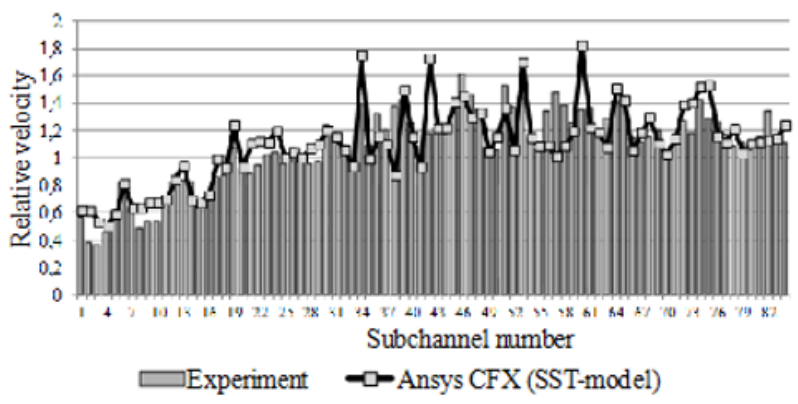

Fig. 5. Relative velocity distribution by subchannels before the spacing grid

\section{Conclusions}

The results of experimental and numerical simulation of hydrodynamic processes occurring in the inlet region of the RITM reactor fuel assembly model are considered. The obtained results of CFD-simulation can be used to determine the input boundary conditions for subchannel programs of the core thermal-hydraulic analysis. This allows taking into account uneven flow ratëëe distribution in subchannels due to the complex geometry of the fuel assembly inlet region.

The research was carried out within the basic part of the grant from the Russian Science Foundation (project № 18-19-00473).

\section{References}

1. O.B. Samoilov, V.I. Alekseev, V.Y. Galitskikh, A.V. Belin, A.N. Zaglyadnov, V.V. Samusenkov, Atomic Energy 121, 6, 389-396 (2017)

2. D.L. Zverev, A.N. Pakhomov, V.I. Polunichev, K.B. Veshnyakov, S.V. Kabin, Atomic Energy 113, 6, 404-409 (2013)

3. V.V. Petrunin, Yu.P. Fadeev, L.V. Gureeva, S.E. Skorodumov, Atomic Energy 111, 5, 355-360 (2012)

4. A.M. Bakhmet'ev, O.A. Bykh, D.V. Shchekin, O.V. Makarov, M.A. Kamnev, M.A. Antonenkov, Atomic Energy 121, 6, 397-401 (2017)

5. V.M. Belyaev, K.B. Veshnyakov, V.G. Zhukovsky, Proc. of the Krylov state research centre 89, 7-20 (2015) 
6. N.N. Melnikov, S.A. Gusak, V.A. Naumov, Vestnik of MSTU 20(1) (2017)

7. M.M. Kashka, A.A. Smirnov, S.A. Golovinsky, Arctic Ecology and economy 3(23), 98107 (2016)

8. V.I. Solonin, P.V. Markov, Transport reactor units (Moscow, Moscow Bauman Moscow State Technical University, 2015)

9. Reactor installations for nuclear icebreakers and optimized floating power units [Electronic resource] Access Mode: http://www.okbm.nnov.ru/images/pdf/ritm200_extended_ru_web.pdf

10. S.M. Dmitriev, D.L. Zverev, O.A. Byh, Y.K., N.M. Sorokin, V.A. Farafonov, Main equipment of nuclear power plants with thermal reactors (Moscow, Mashinostroenie, 2013)

11. K.Yu. Knyazevskiy, Yu.P. Fadeev, A.N. Pakhomov, V.I. Polunichev, Arctic: ecology and economics 3(15), 86-91 (2014)

12. S.M. Dmitriev, A.A. Dobrov, M.A. Legchanov, A.E. Khrobostov, Devices and Methods of Measurements 6(2), 188-195 (2015)

13. S.M. Dmitriev, A.E. Khrobostov, A.V. Varentsov, A.A. Dobrov, D.V. Doronkov, Thermal Engineering 61, 8, 558-565 (2014)

14. A.A. Barinov, S.M. Dmitriev, A.E. Khrobostov, O.B. Samoilov, Atomic Energy, 120, 5, 335-341 (2016)

15. A.A. Gukhman, Introduction to the theory of similarity (Moscow, High school Publ., 1973)

16. S.M. Dmitriev, A.A. Dobrov, G.Sh. Iksanova, K.A. Martynova, Numerical study of coolant hydrodynamics in inlet nozzle of RITM-200 nuclear reactor fuel assembly, Procs. of NNSTU n.a. R.E. Alekseev, 1 (2017)

17. S.M. Dmitriev, A.A. Deulin, A.A. Dobrov, M.A. Legchanov, A.E. Khrobostov, Control systems and information technologies 3.2(57), 232-234(2014)

18. S.M. Dmitriev, A.A. Dobrov, M.A. Legchanov, A.E. Khrobostov Modeling of Coolant Flow in the Fuel Assembly of the Reactor of a Floating Nuclear Power Plant Using the Logos CFD Program, Journal of Engineering Physics and Thermophysics, no. 5 (2015)

19. S.M. Dmitriev, A.A. Dobrov, M.A. Legchanov, A.E. Khrobostov, Procs. of NNSTU n.a. R.E. Alekseev, 88(5), 1297-1303 (2016)

20. S.M. Dmitriev, A.V. Varentsov, A.A. Dobrov, D.V. Doronkov, A.N. Pronin, V.D. Sorokin, A.E. Khrobostov, Journal of Engineering Physics and Thermophysics 90 (4), 941-950 (2017) 